\title{
SOBRE O MANIFESTO "A PEDAGOGY OF MULTILITERACIES: DESIGNING SOCIAL FUTURES" - 20 ANOS DEPOIS
}

\section{ON THE "PEDAGOGY OF MULTILITERACIES: DESIGNING SOCIAL FUTURES" - 20 YEARS ON}

\section{Petrilson Alan Pinheiro*}

O termo "multiletramentos" surgiu pela primeira vez no Manifesto, publicado em 1996, chamado A pedagogy of multiliteracies: designing social futures, de um grupo de pesquisadores intitulados The New London Group $(N L G)^{1}$. De lá para cá, passaramse vinte anos e, nesse período, tem havido muitas publicações, não apenas nos países anglófonos, mas no mundo inteiro, em particular no Brasil, sobre a relação entre (multi)letramentos e o uso de novas tecnologias, influenciadas direta ou indiretamente pela "pedagogia dos multiletramentos".

A proposta do Manifesto é voltada para os estudos semióticos dos textos, envolvendo diferentes formas de produção, veiculação e consumo, expandindo, assim, o conhecimento sobre letramentos. Pode-se, portanto, dizer que o grupo procura apontar, de alguma forma, que o letramento escolar grafocêntrico, mesmo sendo importante, não é suficiente para dar conta das mudanças constantes, sobretudo tecnológicas, que ocorrem tanto local quanto globalmente.

Para expandir essa compreensão sobre multiletramentos, o grupo se apoia em dois argumentos que se enquadram em uma (nova) ordem global, cultural e institucional emergente: "a multiplicidade de canais e meios de comunicação e a crescente saliência de diversidade linguística e cultural" (NLG, 1996, p. 63). O primeiro argumento está relacionado "à crescente multiplicidade e integração de modos de construção de significado, em que o textual está integrado ao visual, ao áudio, ao espacial e ao comportamental, etc. Isso é particularmente importante

\footnotetext{
*Universidade estadual de Campinas, Campinas (SP), Brasil. petrilsonpinheiro@yahoo.com.br

${ }^{1}$ O NLG era composto pelos seguintes membros: Allan Luke, William Cope, Carmen Luke, Courtney Cazden, Charles Eliot, Gunther Kress, Jim Gee, Martin Nakata, Mary Kalantzis, Norman Fairclough, Sarah Michaels.
} 
na mídia de massa, na multimídia e na hipermídia eletrônica" (NLG, 1996, p. 64). O segundo apoia-se nas diferenças culturais, linguísticas e pragmáticas da nossa sociedade. Para o NLG $(1996,64)$, "[u]ma efetiva cidadania e um trabalho produtivo requerem que possamos interagir efetivamente usando múltiplas linguagens, em múltiplos ingleses e padrões de comunicação que cruzam fronteiras nacionais, culturais e comunitárias".

Com base nesses dois argumentos, o grupo chama a atenção para o fato de que as vivências dos estudantes, cada vez mais globais, permite-lhes lidar com uma imensa diversidade linguística e cultural. Assim, o NLG defende um ensino voltado para projetos que considerem essa diversidade e deem visibilidade às dimensões profissional, pessoal e de participação cívica.

Para contemplar essas três dimensões da vida social, o grupo propôs um conceito-chave da pedagogia dos multiletramentos: o design - uma (re)apropriação do termo "design" da dimensão profissional (mundo do trabalho) para as outras duas dimensões da vida social (pessoal e de participação cívica), na tentativa de colocá-las também sob escrutínio de interpretações e ressignificações possíveis em diferentes contextos, tornando-as suscetíveis ao dinamismo, interesse pessoal e capacidade de transformação. Para o NLG, então, o design se forma por meio de um processo de construção de sentidos cuja constituição se dá pela inter-relação de três componentes básicos: available designs, designing e redesigned².

Em linhas gerais, o available designs é aquilo que é disponibilizado pelas formas de representação, os recursos do contexto, da cultura e das convenções. $\mathrm{O}$ designing se caracteriza pela capacidade de desenvolver e transformar um conteúdo conhecido para dele se apropriar convenientemente. O redesigned, por sua vez, realiza-se por meio do que pode ser reorganizado pelo sujeito e reconfigurado para o seu mundo, abarcando, por assim dizer, a própria ação durante o processo de construção de significados.

Segundo o NLG, o que subjaz a todo o processo de design é a ideia de que o estudante deve reconhecer e usar os "designs disponíveis" (available designs) de várias modalidades materiais/simbólicas para planejar, construir (designing), e criticamente replanejar e reconstruir (redesigning) suas identidades, oportunidades e futuros como cidadãos globais de um mundo complexo e crescentemente conectado. Para viabilizar

\footnotetext{
${ }^{2} \mathrm{O}$ termo design, na concepção com a qual se lida neste texto, engloba tanto um sentido mais restrito, isto é, uma instanciação de convenções e recursos construídos e reificados socioculturalmente, como também um sentido mais amplo, o de um processo de retrabalho que leva a sua própria ressignificação, transformação. Dada a ambivalência do termo e a possibilidade de a tradução para o português não contemplar ou mesmo distorcer tal ambivalência, a opção foi deixar o termo em inglês.
} 
ou operacionalizar esse processo, o "quê" da pedagogia dos multiletramentos, o NLG relacionou-o a quatro componentes, que seriam o "como" dessa pedagogia: prática situada (situated practice), instrução explícita (overt instruction), enquadramento crítico (critical framing) e prática transformada (transformed practice).

Em linhas gerais, a prática situada envolve experiências de mundo e significados situados em contextos do mundo real. Nela, são priorizados designs criados pelos alunos e/ou professores, envolvendo simulações de seus contextos locais, que se relacionam ao mundo do trabalho ou a situações que ocorrem em espaços públicos. $\mathrm{Na}$ instrução Explícita, trabalha-se a metalinguagem usada por alunos e professores em favor de uma compreensão sistemática, analítica e consciente das instruções e dos conteúdos, vislumbrando sua aplicabilidade em situações específicas de aprendizagem, de modo a explicitar diferentes modos de significação. O enquadramento crítico se constitui por meio de análise e interpretação do contexto social e cultural, de políticas, ideologias e valores explícitos ou implícitos, tendo como referência os designs desenvolvidos. Por fim, a prática transformada seria, então, o resultado da transferência e a recriação de sentidos consolidados por meio da transposição/intervenção inovadora em diferentes contextos. Nesse movimento, torna-se explícita a construção de um novo sentido, tendo por referência um contexto inicial ou uma prática situada.

Cabe, contudo, aqui uma reflexão mais ampla sobre o design. É preciso, primeiramente, problematizar a própria relação entre o "quê" e o "como" dos multiletramentos. Nesse sentido, vale notar que toda construção de conhecimento, incluindo a que acontece nas aulas consideradas mais "tradicionais", passa pelo processo que engloba os três componentes básicos: available designs, designing e redesigned. Mesmo uma aula que se pauta por uma perspectiva normativa de ensino de gramática, por exemplo, envolve um processo que inclui recursos disponibilizados aos alunos - advindos da própria gramática, não necessariamente normativa - e por eles ressignificados por meio de textos, atividades, explicações e posturas do professor, que pode até contribuir para transformar uma gramática com viés reflexivo em um material de cunho normativo. Nesse exemplo, os componentes de "quê" dos multiletramentos não seriam mobilizados pelos elementos do "como" (prática situada, instrução explícita, enquadramento crítico e prática transformada), mas por outro(s) processo(s). Assim, pode-se afirmar que toda prática transformada é um redesigned, mas nem todo redesigned se torna necessariamente uma prática transformada. Para que haja de fato tal correlação, é preciso que os quatro elementos sejam partes constitutivas do design. 
Outra questão a ser problematizada - e que também parece estar subjacente ao Manifesto do NLG - é a ideia de que os letramentos são cada vez mais influenciados por dois efeitos globais: a expansão da comunicação de massa (atualmente compartilhada em escala mundial) e a massificação das novas tecnologias de informação e comunicação (TIC). Obviamente, é fundamental que se compreenda que as transformações de ordem social, política e cultural são também o corolário de mudanças no mundo do trabalho, decorrentes de processos de globalização, incluindo nesse bojo a ubiquidade das TIC. Todavia, se essa relação for levada a ferro e fogo, sem consideração de seus matizes, corremos o risco de ser guiados por uma perspectiva que se enquadra exclusivamente na dinâmica de reestruturação do capitalismo, que se consolida no modelo vigente neoliberal. Tal perspectiva pode conduzir (e, em muitos contextos, já conduz!) à criação de modelos de ensino que se enquadram em lógicas mercadológicas, sugeridas e até, em alguns casos, impostas por grandes conglomerados e corporações internacionais. Nessas lógicas, práticas de competitividade, produtividade e utilitarismo - bases do discurso neoliberal -, podem, em última instância, transformar a educação em commodities, ou, como já dizia Marx (1985 [1867], p. 45), em uma "imensa coleção de mercadorias", cujo papel seria mais direcionado e dimensionado pela utilidade e função que desempenhariam no/para o mercado, como muitos parecem desejar!

Assim, uma alternativa para lidar com a questão do design, sem cair na "lógica do mercado", seria tentar entendê-lo segundo outra lógica: aquela em que a relação local-global se constitui dialeticamente. Em sociedades cada vez mais dinâmicas, cosmopolitas e tecnologizadas, na qual as ações globais são cada vez mais afetadas pelas ações locais e vice-versa: por um lado, o local se torna rapidamente transnacional e, por outro, o global chega às mais longínquas localidades do planeta. O "global está localizado e o local está globalizado" (KUMARAVADIVELU, 2006, p. 134).

Ao buscar articular essa relação local-global com a perspectiva do design com a qual lida o NLG, é possível, então, desenvolver uma crítica mais específica sobre a proposta do grupo, que se funda em outra relação: texto e prática. Em relação ao primeiro componente do "como" dos multiletramentos, pode-se dizer que, embora o NLG aponte que a prática situada envolve experiências e interesses dos alunos, estes são mobilizados para entender de que formas os textos trabalham para estruturar significados, intenções e possibilidades presentes em diversos contextos sociais, buscando, de alguma forma, fazer simulações de seus contextos locais e sua relação com o mundo do trabalho ou com situações que ocorrem em espaços públicos. Nesse sentido, percebe-se que as práticas de letramentos dos discentes, 
direcionados pelo professor para que se tornem designers de seus futuros sociais, são tomadas como designs intencionais e racionais.

Ao privilegiar o texto como resultado e intenção das práticas de letramentos por meio do uso dos recursos disponíveis e de seu replanejamento e reconstrução (redesigned), o NLG, então, lida com uma noção de "prática" primariamente dirigida por uma orientação racional em relação ao futuro. Assim, a ideia de desenvolver o design de textos para realizar objetivos já conhecidos é projetada nos estudantes como a (única) trajetória a ser percorrida. Nesse sentido, pode-se dizer que suas identidades seriam relativamente valorizadas, visto que constituídas da mesma forma que seus textos, isto é, como elementos a serem planejados para projetos futuros racionalmente controlados. Com isso, a visão de "prática" subjacente à pedagogia dos multiletramentos apresenta certa domesticação (ou escolarização), que escamoteia aspectos contingenciais inerentes às práticas, como o movimento e a indeterminação.

A relação texto-prática também pode ser vista no segundo componente da perspectiva do design: a instrução explícita. Nela, como foi apontado acima, trabalhase a metalinguagem usada por alunos e professores em favor de uma compreensão sistemática, analítica e consciente de um determinado conteúdo. Contudo, se a ideia é conceber a origem e o ambiente a partir do qual o texto seria constituído, o uso da metalinguagem por meio de instrução explícita deveria ser o corolário das práticas dos estudantes no contexto escolar, e não o contrário. É o caso, por exemplo, do aluno que, lendo o poema "Morro da Babilônia", de Carlos Drummond de Andrade, em uma aula de língua portuguesa, infere metonimicamente a relação entre a cidade do Rio de Janeiro e o Morro da Babilônia, mesmo sem ter formalmente aprendido o que é metonímia. Ou o caso de um grupo de alunos que, sem nunca ter aprendido nada sobre planos e ângulos de câmera, produz um vídeo sobre homofobia para um projeto temático e intuitivamente faz uso de um ângulo de câmera contra-plongé - câmera abaixo do nível dos olhos, voltada para cima - para filmar um personagem homofóbico, com o intuito de mostrar o poder do discurso desse personagem na sociedade em que vive. Nesse sentido, para compreender conteúdos e vislumbrar sua aplicabilidade em situações específicas de aprendizagem, é preciso que esses conteúdos façam sentido para os alunos, e sejam, de alguma forma, parte das práticas com as quais lidam.

Essa visão, que parte da prática para o texto, por sua vez, possibilita um enquadramento crítico que busca fazer uma análise e interpretação de questões sociais, culturais, políticas e ideológicas, tendo como referência não apenas os designs moldados a priori pelos textos, mas também o que se denomina aqui designs 
contingenciais, nos quais operam movimentos, indeterminações e dissonâncias. Basta pensar, por exemplo, na Wikipédia, a enciclopédia online mais acessada do mundo, construída com base na contribuição de verbetes por parte dos próprios usuários. A noção de conhecimento que subjaz à concepção da Wikipédia obriga não apenas a consumi-la, mas, sobretudo, a analisá-la de forma crítica, diferentemente do que fazemos com os textos impressos. Isso, contudo, só é possível, se se considerar a Wikipédia um design contingencial.

$\mathrm{O}$ impacto que a ideia de design contingencial pode ter para a noção de letramentos é, de fato, interessante. Em uma era em que lidamos com um "saberfluxo", não basta "reconhecer e consumir conteúdos que circulam na internet, mas buscar compreender e avaliar os diferentes mecanismos que regem a produção, reprodução e difusão desses conteúdos" (PINHEIRO, 2010, p. 211). Isso, por sua vez, afetará sobremaneira a prática transformada, entendida, portanto, como resultado, de fato, da recriação de sentidos por meio de uma intervenção inovadora em diferentes contextos; a construção de novo(s) sentido(s), tendo por base designs contingenciais, caracterizados por serem efêmeros e multifacetados.

\section{REFERÊNCIAS BIBLIOGRÁFICAS}

KUMARAVADIVELU, B. A Linguística Aplicada na Era da Globalização. In: MOITA

LOPES, L.P. (Org.). Por uma linguística Aplicada Indisciplinar. São Paulo: Parábola, p. 129-148. 2006.

MARX, Karl. O capital: crítica da economia política. 2. ed. São Paulo: Nova Cultural, 1985. (Os economistas). [Publicado originalmente em 1867].

PINHEIRO, P. A. Web 2.0 e saber-fluxo: novas questões de letramento digital. Confluência - Revista do Instituto de Língua Portuguesa, n. 37-38, p. 193-214, 2010.

THE NEW LONDON GROUP. Multiliteracies: Literacy learning and the design of social futures. London: Routledge, 2000. 